Check for updates

Cite this: RSC Adv., 2017, 7, 23478

Received 2nd March 2017 Accepted 24th April 2017

DOI: $10.1039 / c 7 r a 02593 a$

rsc.li/rsc-advances

\section{Synthesis and characterization of flower-like $\mathrm{MoO}_{3} / \mathrm{In}_{2} \mathrm{O}_{3}$ microstructures for highly sensitive ethanol detection $\uparrow$}

\author{
Jie Hu, (D) *a Xiu Wang, ${ }^{a}$ Meng Zhang, ${ }^{a}$ Yongjiao Sun, ${ }^{a}$ Pengwei Li, (D) ${ }^{a}$ \\ Wendong Zhang, ${ }^{a}$ Kun Lian, ${ }^{a}$ Lin Chen ${ }^{\star b}$ and Yong Chen ${ }^{c}$
}

\begin{abstract}
Flower-like pure and Mo-loaded $\ln _{2} \mathrm{O}_{3}$ hierarchical microstructures were synthesized by a facile hydrothermal method. The morphology, crystal structures, and compositions of the samples were characterized by SEM, XRD, TEM, showing nanosheets with dimensions of $4 \mu \mathrm{m}$ diameter and $25 \mathrm{~nm}$ thickness. Gas sensing experiments were conducted on the as-prepared $\mathrm{MoO}_{3} / \mathrm{ln}_{2} \mathrm{O}_{3}$ gas sensors, and the results prove that Mo-loaded $\ln _{2} \mathrm{O}_{3}$ gas sensors exhibit enhanced gas sensing properties at $185^{\circ} \mathrm{C}$. In particular, the $3 \mathrm{~mol} \%$ Mo-loaded $\ln _{2} \mathrm{O}_{3}$ provided a high response (7 to $100 \mathrm{ppm}$ ethanol), fast response and recovery time (11 s and $94 \mathrm{~s}$ ), low detection limit (50 ppb), good selectivity and stability for ethanol detection, which is promising for low concentration ethanol detection in practical applications.
\end{abstract}

\section{Introduction}

In the past decades, metal oxide semiconductor (MOS) gas sensors, such as $\mathrm{ZnO},{ }^{1} \mathrm{SnO}_{2},{ }^{2} \mathrm{In}_{2} \mathrm{O}_{3},{ }^{3} \mathrm{WO}_{3},{ }^{4} \mathrm{Cr}_{2} \mathrm{O}_{3},{ }^{5} \mathrm{CuO},{ }^{6}$ etc. , have attracted tremendous attention owing to their domestic and industrial applications for detection of explosive gases, toxic gases, and volatile organic compounds (VOCs). Among them, indium oxide $\left(\operatorname{In}_{2} \mathrm{O}_{3}\right)$, an important n-type semiconductor with a direct band gap of 3.55-3.75 eV, has been reported as the best potential gas sensing material due to its good conductivity and high stability. ${ }^{7-10}$ Furthermore, $\operatorname{In}_{2} \mathrm{O}_{3}$ has been produced in different forms of nanostructures, such as nanowires, nanospheres, nanorods, nanoporous and nanofibers, showing interesting gas sensing capabilities for various gases including nitric oxide, ${ }^{11}$ methane, ${ }^{12}$ ammonia, ${ }^{13}$ acetone ${ }^{14}$ and ethanol. ${ }^{15}$

More recently, numerous studies have demonstrated that the gas sensing properties of MOS materials are not only highly dependent on the morphology, surface to volume ratio, crystalline size, exposed surface, etc. ${ }^{16-18}$ but also related to the further functionalization with other metals, graphene and so on. ${ }^{19-21}$ In particular, many researchers have reported that the introducing of dopant element into $\mathrm{In}_{2} \mathrm{O}_{3}$ sensing materials

${ }^{a}$ Micro and Nano System Research Center, Key Lab of Advanced Transducers and Intelligent Control System (Ministry of Education), College of Information Engineering, Taiyuan University of Technology, Taiyuan 030024, Shanxi, China. E-mail: hujie@tyut.edu.cn

${ }^{b}$ Research Center on Advanced Materials Science and Technology, Taiyuan University of Technology, Taiyuan 030024, Shanxi, China. E-mail: chenlin01@tyut.edu.cn ${ }^{c}$ Ecole Normale Supérieure, CNRS-ENS-UPMC UMR 8640, Paris 75005, France

$\dagger$ Electronic supplementary information (ESI) available. See DOI: $10.1039 / \mathrm{c} 7 \mathrm{ra02593a}$ may causes the change of crystalline structure and grain size as well as impurity levels and surface defects, which can significantly improve the gas sensing performances of $\operatorname{In}_{2} \mathrm{O}_{3}$ gas sensors. ${ }^{22-24}$ For example, Han et al. reported that Ce-doped $\mathrm{In}_{2} \mathrm{O}_{3}$ gas sensors exhibited a response of 35.2 towards $100 \mathrm{ppm}$ methanol, which is about 2.2 times as high as the pure $\operatorname{In}_{2} \mathrm{O}_{3}$ gas sensor. ${ }^{25}$ Zheng et al. have demonstrated that the response of Pt nanoparticles decorated $\mathrm{In}_{2} \mathrm{O}_{3}$ nanofibers

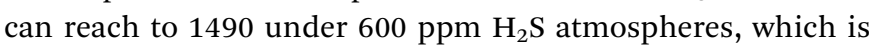
about 10 times higher than that of the pure one. ${ }^{26}$ By electrospinning and subsequent calcination, Chi et al. have fabricated $\mathrm{Fe}_{2} \mathrm{O}_{3}-\mathrm{In}_{2} \mathrm{O}_{3}$ nanotubes with a response of 33 to $100 \mathrm{ppm}$ formaldehyde, and the obtained response is about double of the pure $\mathrm{In}_{2} \mathrm{O}_{3}$ nanotubes. ${ }^{27} \mathrm{Up}$ to now, although considerable efforts have been focused on the study of the influence of doping unique elements to the sensing performances, to the best of our knowledge, studies of $\mathrm{MoO}_{3} / \mathrm{In}_{2} \mathrm{O}_{3}$ hierarchical microstructures optimized the doping content have rarely been reported.

Herein, we report a facile method for the preparation of $\mathrm{MoO}_{3} / \mathrm{In}_{2} \mathrm{O}_{3}$ flower-like hierarchical microstructures by a simple hydrothermal method. The morphology, crystalline structures, and compositions of the samples were characterized using different techniques. The gas sensing performances of pure and Mo-loaded $\operatorname{In}_{2} \mathrm{O}_{3}$ microstructures to ethanol were investigated under different working temperatures. The results indicate that the introducing of Mo element can significantly improve the gas sensing properties of $\operatorname{In}_{2} \mathrm{O}_{3}$-based sensors, which can be explained by considering the change of the band structures of the samples. 


\section{Materials and methods}

\subsection{Materials}

Indium chloride tetrahydrate $\left(\mathrm{InCl}_{3} \cdot 4 \mathrm{H}_{2} \mathrm{O}, \geq 97 \%\right)$ and ammonium molybdate tetrahydrate $\left(\left(\mathrm{NH}_{4}\right)_{6} \mathrm{Mo}_{7} \mathrm{O}_{24} \cdot 4 \mathrm{H}_{2} \mathrm{O}, \geq 99.98 \%\right)$ were obtained from Sigma-Aldrich (Shanghai, China). Sodium dodecyl sulfate $\left(\mathrm{C}_{12} \mathrm{H}_{25} \mathrm{SO}_{4} \mathrm{Na}\right.$, SDS, $\left.\geq 99 \%\right)$ and urea $\left(\mathrm{CO}\left(\mathrm{NH}_{2}\right)_{2}\right.$, $\geq 99 \%$ ) were purchased from Sinopharm Chemical Reagent Co. Ltd., China. The other chemical reagents were used analytical grade without any further purification.

\subsection{Preparation of flower-like Mo-loaded $\operatorname{In}_{2} \mathrm{O}_{3}$ microstructure}

In a typical process, $1.2 \mathrm{mmol}$ of $\mathrm{InCl}_{3} \cdot 4 \mathrm{H}_{2} \mathrm{O}, 3.6 \mathrm{mmol}$ of SDS and $6 \mathrm{mmol}$ of urea were dissolved into $72 \mathrm{~mL}$ of deionized (DI) water. After that, different amounts of $\left(\mathrm{NH}_{4}\right)_{6} \mathrm{Mo}_{7} \mathrm{O}_{24} \cdot 4 \mathrm{H}_{2} \mathrm{O}(0$, 1,3 and $5 \mathrm{~mol} \%$ ) were added into the mixed solution with vigorous stirring for $30 \mathrm{~min}$ at room temperature. Then, the obtained solution was transferred into a $72 \mathrm{ml}$ Teflon-lined stainless steel autoclave, sealed tightly, maintained at $120{ }^{\circ} \mathrm{C}$ for $12 \mathrm{~h}$. After cooled to room temperature naturally, the precipitates were collected by centrifugation and then washed with DI water and ethanol for several times. The fine powders were obtained after dried at $80^{\circ} \mathrm{C}$ for $24 \mathrm{~h}$ in oven. Finally, the samples were calcined in a muffle furnace at $600{ }^{\circ} \mathrm{C}$ for $3 \mathrm{~h}$, and the calcined products were then collected for further analyses. For convenience, the molar ratio of $\mathrm{Mo} / \mathrm{In}(0,1,3$ and $5 \mathrm{~mol} \%)$ were defined as $\mathrm{Mo}_{0} \mathrm{In}, \mathrm{Mo}_{1} \mathrm{In}, \mathrm{Mo}_{3} \mathrm{In}$ and $\mathrm{Mo}_{5} \mathrm{In}$, respectively.

\subsection{Characterization}

The crystal phase and crystallinity of as-synthesized products were analyzed by X-ray diffraction (XRD, Haoyuan, China) with $\mathrm{Cu} \mathrm{K} \alpha_{1}$ radiation $(\lambda=1.5406 \AA)$ in the range of $20-80^{\circ}$. The morphology and structure of Mo-loaded $\operatorname{In}_{2} \mathrm{O}_{3}$ were observed by using scanning electron microscope (SEM, JSM-7001F, Japan) and transmission electron microscopic (TEM, JEOL-2010F, Japan) at an accelerating voltage of $10 \mathrm{kV}$ and $200 \mathrm{kV}$, respectively. The element compositions of the samples were characterized by the energy dispersive X-ray spectroscopy (EDS, Bruker) and the chemical state was investigated by X-ray photoelectron spectroscopy (XPS, Thermo Electron, U.K.) with monochromatic $\mathrm{Al} \mathrm{K} \alpha(1486.6 \mathrm{eV})$ irradiation.

\subsection{Fabrication and measurement of gas sensor}

The fabrication process of Mo-loaded $\mathrm{In}_{2} \mathrm{O}_{3}$ gas sensors can be described as follows. The obtained powders were firstly mixed with terpineol and ethyl cellulose (weight ratio $2: 8: 1$ ) to form symmetrical slurry. Then, the slurry was carefully coated on the surface of alumina ceramic tube as sensing film with a pair of Au electrodes and Pt wires (Fig. 1(a)). Subsequently, the sensing element was dried at $80{ }^{\circ} \mathrm{C}$ for $10 \mathrm{~h}$ in air and annealed at $600{ }^{\circ} \mathrm{C}$ for $2 \mathrm{~h}$ to improve the mechanical strength. After that, a small $\mathrm{Ni}$-Cr wire $(\sim 45 \Omega)$ was inserted into the alumina tube as heater to control the operating temperature of the sensor. After soldered on the pedestal (Fig. 1(b)), the gas sensor was aged at

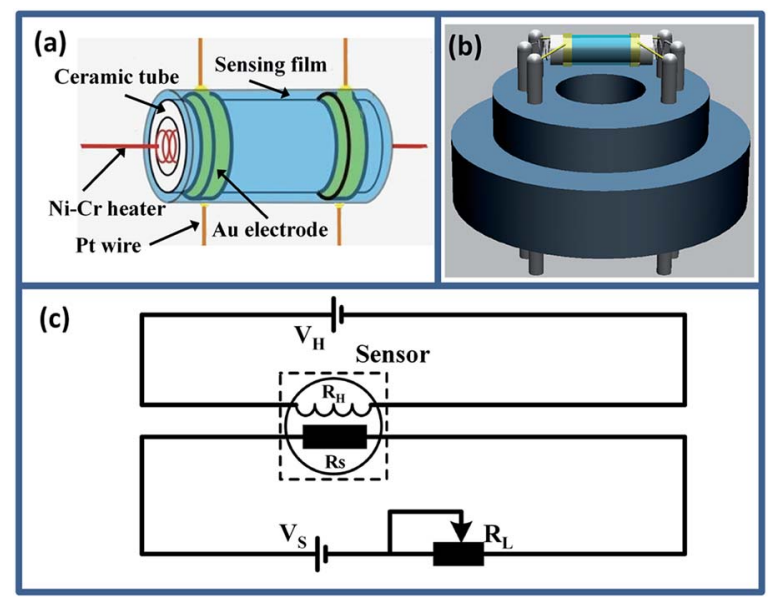

Fig. 1 (a) Schematic illustration of gas sensing element. (b) The 3D schematic diagram of gas sensor. (c) The working principle of the electrical circuit for measuring the as-prepared gas sensors.

$5 \mathrm{~V}$ for 3 days in air to improve the long-term stability and repeatability.

The gas sensing properties of as-prepared sensors were measured using CGS-1TP intelligent analysis system (Elite, Beijing, China), and all the measures were performed under the controlled relative humidity $(\mathrm{RH}) 30 \% \pm 5 \%$. Fig. 1 (c) shows the schematic diagram of the electrical circuit for measuring the pure and Mo-loaded $\operatorname{In}_{2} \mathrm{O}_{3}$ gas sensors. In the measuring electric circuit of gas sensor, the heating voltage $\left(V_{\mathrm{H}}\right)$ is used to control the working temperature by heating the $\mathrm{Ni}-\mathrm{Cr}$ wire. The load resistor $\left(R_{\mathrm{L}}\right)$ is connected in series with the as-fabricated gas sensor. The circuit voltage $V_{\mathrm{S}}$ is $5 \mathrm{~V}$, and the output voltage $\left(V_{\text {out }}\right)$ is the terminal voltage of the load resistor $R_{\mathrm{L}}$. During the gas sensing experiments, the gas sensors were placed into the testing chamber $(18 \mathrm{~L})$, and the target gas was injected into the chamber using microsyringe. The response was defined as the ratio of the resistance in air to the resistance in target gas $\left(R_{\mathrm{a}} / R_{\mathrm{g}}\right)$. The response and recovery time was expressed as the time taken for the sensor to reach $90 \%$ of the total resistance change in the case of adsorption and desorption, respectively.

\section{Results and discussion}

\subsection{Morphology and structure analysis}

Fig. 2(a) depicts the XRD pattern of Mo-loaded $\operatorname{In}_{2} \mathrm{O}_{3}$ microstructures with different concentrations of Mo after calcination. The measured results show that all the diffraction peaks are matched well with $\mathrm{In}_{2} \mathrm{O}_{3}$ (JCPDS File no. 06-0416), and no other characteristic peaks can be found in the spectrum of samples, which indicates the high purity of the final products. Meanwhile, there is also no apparent peak of Mo can be detected, which is possibly due to the low concentration of Mo in the sample. Fig. 2(b) exhibits the magnified image of the peak (440) for as-synthesized $\operatorname{In}_{2} \mathrm{O}_{3}$ microstructures. It can be found that all the diffraction peaks are slightly shift to a higher angle, which might be due to lattice strain by the formation of $\mathrm{Mo}^{6+}$ 

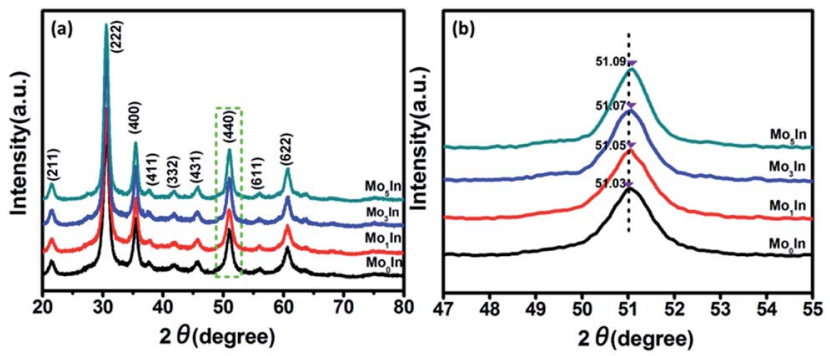

Fig. 2 (a) X-ray diffraction patterns of as-synthesized microstructures. (b) High magnification of the (440) peaks.

ions (the ionic radius of $\mathrm{Mo}^{6+}(0.59 \AA)$ is smaller than that of $\operatorname{In}^{3+}$ $(0.8 \AA)$ in the loaded $\mathrm{In}_{2} \mathrm{O}_{3}$ microstructures $)^{28}$ The similar results have been reported in previous works. ${ }^{29-31}$ In addition, Fig. S1 (ESI S1†) illustrates the XRD patterns of as-synthesized samples before calculation, and the results indicate that the pure and Mo-loaded $\operatorname{In}_{2} \mathrm{O}_{3}$ samples can be obtained after calcination in a muffle furnace at $600{ }^{\circ} \mathrm{C}$ in air atmosphere.

The morphological characteristics of the as-synthesized hierarchical flower-like samples were observed by SEM. Fig. 3(a) shows the SEM image of flower-like $\operatorname{In}_{2} \mathrm{O}_{3}$ microstructures, and the average diameter of microspheres is about $4 \mu \mathrm{m}$ assembled with numerous nanosheets. Fig. 3(c) and (d) exhibits the SEM image of $3 \mathrm{~mol} \%$ Mo-doped $\operatorname{In}_{2} \mathrm{O}_{3}$ samples, and the thickness of the nanosheet is only $25 \mathrm{~nm}$ from the inset image (Fig. 3(d)). It seems that the introduction of Mo element has no obvious influence on the morphology of samples, as shown in Fig. S2 (ESI S2 $\dagger$ ). Meanwhile, in order to investigate the composition, the EDS was performed on the sample of $\mathrm{Mo}_{3} \mathrm{In}$, and the measured peaks of In, $\mathrm{O}$ and Mo are all corresponding well with the standard spectrum diagram, which confirms the existence of Mo element in sample. Moreover, the $3 \mathrm{~mol} \% \mathrm{Mo}-$ loaded $\operatorname{In}_{2} \mathrm{O}_{3}$ sample was further confirmed using the elemental mapping. From the Fig. 3(f)-(i), we can found that the spatial distribution of the In, $\mathrm{O}$ and Mo elements exhibits spherical microstructure, which indicates the uniform distributions of Mo element on the sample.
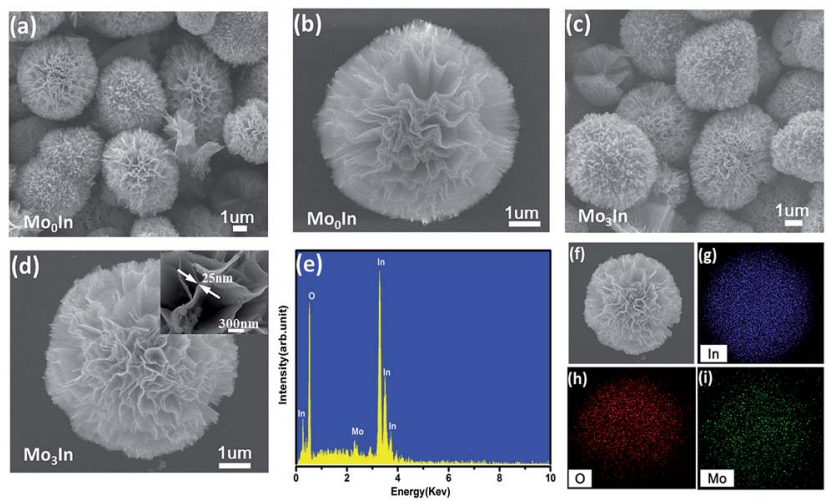

Fig. 3 SEM images of as-synthesized flower-like hierarchical microstructures, ( $a$ and b) $\mathrm{Mo}_{0} \mathrm{In}$, (c and d) $\mathrm{Mo}_{3} \mathrm{In}$. (e) EDS spectrum of $\mathrm{Mo}_{3} \mathrm{In}$. $(\mathrm{f}-\mathrm{i})$ Elemental mapping images of $\mathrm{In}, \mathrm{O}$ and Mo element, respectively.
To further investigate the structural features of Mo-loaded $\operatorname{In}_{2} \mathrm{O}_{3}$ microstructures, TEM and HRTEM combined with the selected area electron diffraction (SAED) techniques were conducted on the sample of $\mathrm{Mo}_{3}$ In. Fig. 4(a) shows the low magnification image of nanosheet, and the lattice fringes can be clearly observed in the high magnification image as Fig. 4(b). The lattice plane spacing was calculated with a periodic value of $0.253 \mathrm{~nm}$ and $0.292 \mathrm{~nm}$ corresponding to the (400) and (222) plane of $\operatorname{In}_{2} \mathrm{O}_{3}$ (Fig. 4(c) and (d)), respectively. Fig. 4(e) illustrates the corresponding SAED pattern of sample. The diffraction circles can be indexed to the (211), (400), (422), (440) and (622) planes of the flower-like $\operatorname{In}_{2} \mathrm{O}_{3}$ microstructure, which indicates the as-synthesized $\operatorname{In}_{2} \mathrm{O}_{3}$ microstructures is polycrystalline. However, it seems that there is no diffraction circle of Mo element, which is possibly due to the low concentration of Mo element in the sample.

In order to determine the surface elements and chemical states of Mo-loaded $\operatorname{In}_{2} \mathrm{O}_{3}$ sample, the XPS measurements were performed on the $\mathrm{Mo}_{3}$ In microstructures. The XPS spectra were calibrated with respect to the binding energy of the $\mathrm{C} 1 \mathrm{~s}$ peak at $284.6 \mathrm{eV}$ and deconvolution with the Casa XPS software. Fig. 5(a) illustrates XPS survey spectra of $\mathrm{Mo}_{3}$ In microstructures, the elements of In, N, O and Mo can be clearly detected in the sample. Fig. 5(b) exhibits the high resolution XPS spectrum of In $3 \mathrm{~d}$ state, which indicates the peaks located at $443.78 \mathrm{eV}$ and $451.38 \mathrm{eV}$ correspond to the In $3 \mathrm{~d}_{5 / 2}$ and In $3 \mathrm{~d}_{3 / 2}$, respectively. The peak separation between In $3 \mathrm{~d}_{5 / 2}$ and In $3 \mathrm{~d}_{3 / 2}$ is $7.6 \mathrm{eV}$, which suggests that In element exists principally in the form of $\mathrm{In}^{3+}$ in sample. From the XPS spectra of O 1s in Fig. 5(c), two peaks centered at $529.28 \mathrm{eV}$ and $530.98 \mathrm{eV}$ can be observed in the sample. The peak located at $529.28 \mathrm{eV}$ can be assigned to the lattice oxygen in the as-synthesized product structure embraced by indium and molybdenum, and the peak at $530.98 \mathrm{eV}$ can be ascribed to the oxygen defects in the metal oxide regions..$^{32,33}$ The Mo 3d pectra (Fig. 5(d)) shows two peaks of the binding energy at $232.63 \mathrm{eV}$ and $235.78 \mathrm{eV}$, which is associated with the Mo $3 \mathrm{~d}_{5 / 2}$ and Mo $3 \mathrm{~d}_{3 / 2}$ on the surface of sample, separately. ${ }^{34,35}$ Meanwhile, the crystal phase of $\mathrm{MoO}_{3}$ can be further confirmed

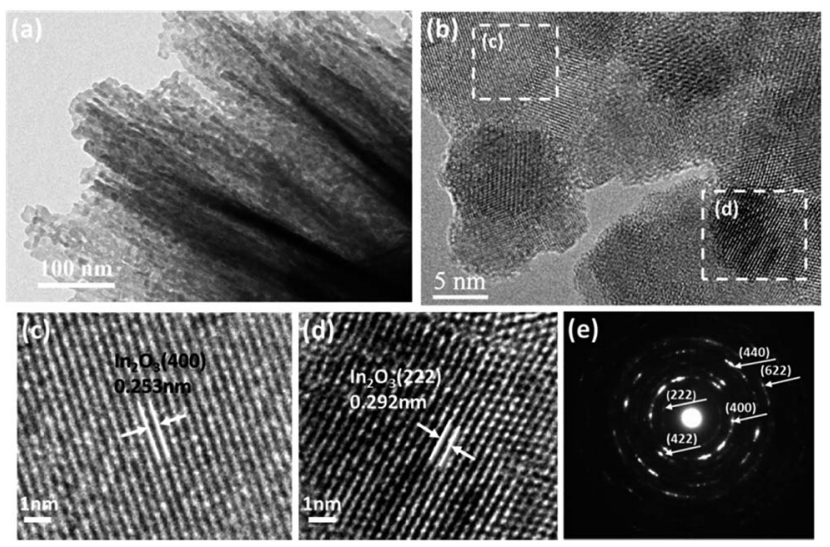

Fig. 4 (a) TEM image of Mozln nanosheets. (b) HRTEM image of Mozln. ( $c$ and d) The enlarged HRTEM images of the marked areas, and (e) the corresponding SAED pattern. 

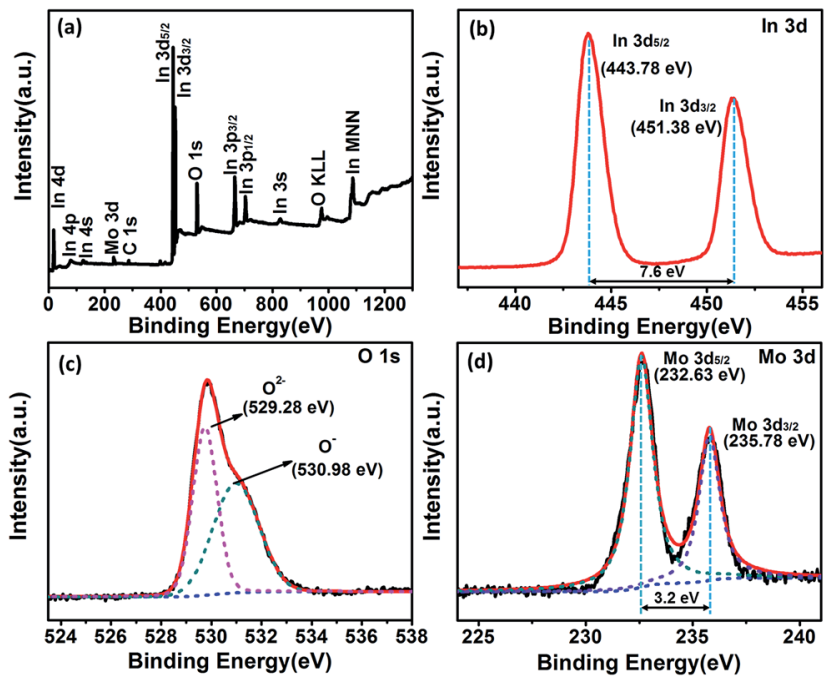

Fig. 5 XPS spectra of the as-synthesized $\mathrm{Mo}_{3}$ In. (a) Full survey scan spectrum, (b) In 3d, (c) $\bigcirc 1$ s and (d) Mo 3d, respectively.

on account of the two peaks separation of $3.2 \mathrm{eV}$, and it indicates the successful introduction of $\mathrm{MoO}_{3}$ in the sample, which consists well with the results of XRD and the elemental mapping of EDS.

\subsection{Gas sensing performance}

As we all know, the operating temperature is most important parameter for a metal oxide semiconductor gas sensor, and the gas response is highly influenced by the working temperature. In order to determine the optimum operating temperature of as-prepared gas sensors, the responses of gas sensors were measured under different operating temperatures varying from $110{ }^{\circ} \mathrm{C}$ to $285^{\circ} \mathrm{C}$. As shown in Fig. 6, it can be clearly observed that the responses of all the gas sensors initially increase with temperature rising and reaching the maximum at $185{ }^{\circ} \mathrm{C}$, and then decrease with further increasing of the operating temperature. Therefore, the optimum working temperature is chosen

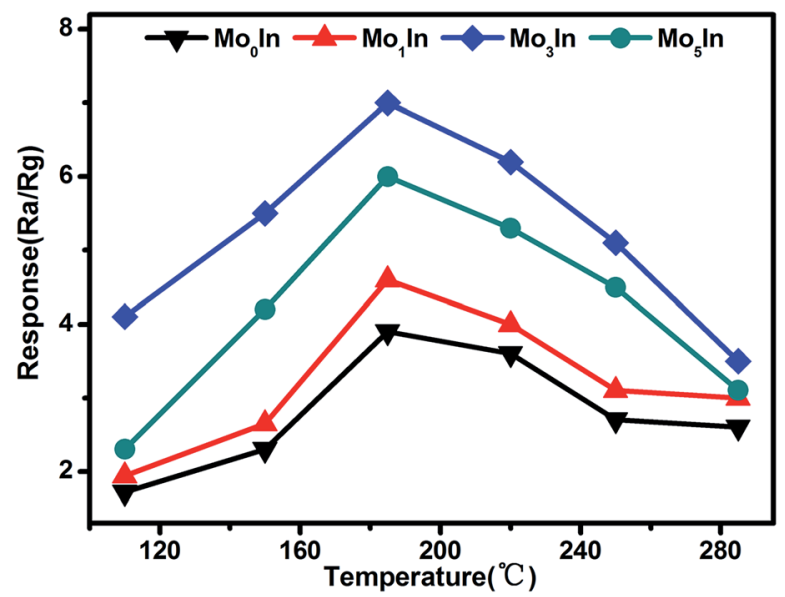

Fig. 6 Response of as-prepared gas sensors upon exposure to 100 ppm ethanol at different working temperatures. as $185^{\circ} \mathrm{C}$, which is applied in all the following investigation of gas sensing performance. For the 'increase-maximumdecrease' tendency of gas response, which could be attributed to the reason as following: when the operating temperature is too low, the absorbed ethanol molecules can't be activated enough to overcome the activation energy barrier to react with the absorbed oxygen species. However, when the operating temperature enhances too much, some absorbed oxygen species maybe escape away before the reaction. ${ }^{36,37}$ Meanwhile, the measured results also demonstrate that Mo-loaded $\operatorname{In}_{2} \mathrm{O}_{3}$ gas sensors exhibit significant enhanced gas response than pure one, which could be ascribed to the introduction of Mo element. Moreover, the $\mathrm{Mo}_{3}$ In gas sensor shows the highest gas response, which is about two times higher than that of pure one. The measured results prove that appropriate $\mathrm{MoO}_{3}$ loading can significantly improve the gas sensing performances of $\operatorname{In}_{2} \mathrm{O}_{3}$ gas sensors, which was demonstrated in our experimental results. However, excessive amount of $\mathrm{MoO}_{3}$ in the samples will reduce the amount of oxygen adsorption and reactive sites, which will suppress the gas sensing properties of gas sensors. ${ }^{38}$

At the same time, the reversibility of Mo-loaded $\operatorname{In}_{2} \mathrm{O}_{3}$ gas sensors were also investigated under different operating temperatures, Fig. 7 shows the corresponding resistance curves of sensors to $100 \mathrm{ppm}$ ethanol under different operating temperatures. The results show that the resistance values of all the as-prepared gas sensors decrease sharply after exposure to ethanol gas, and recovery to the initial value when exposed in fresh air, which exhibit excellent reversibility. Fig. S3 (ESI S3†)

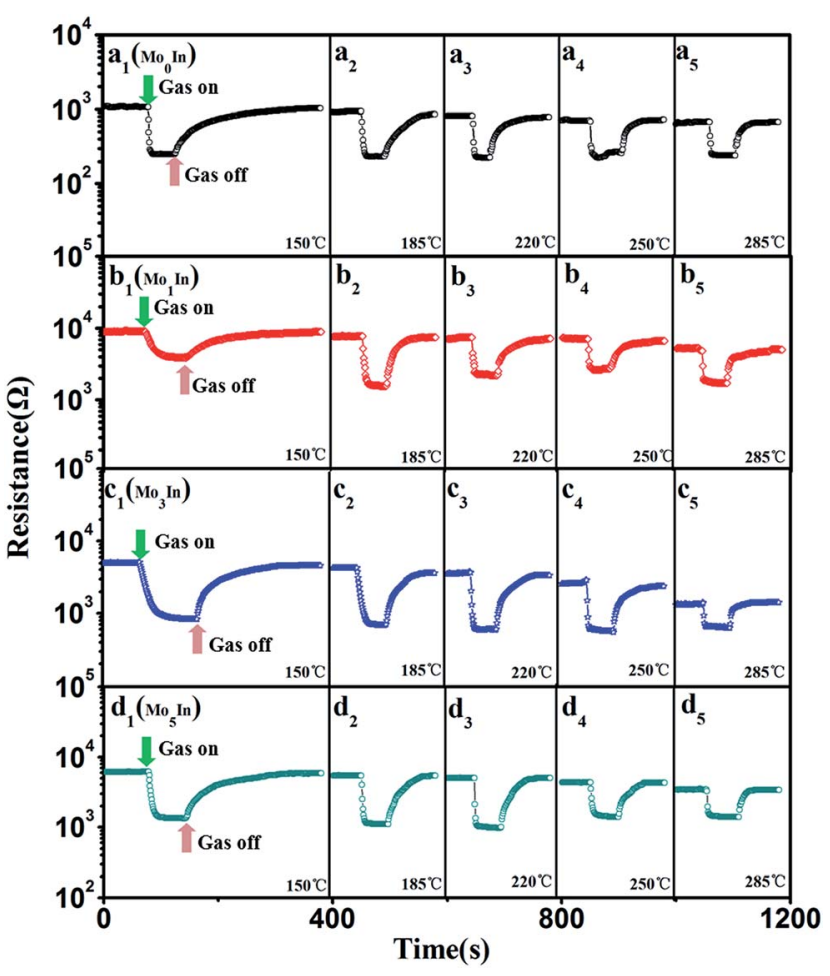

Fig. 7 Resistance of as-prepared $\mathrm{In}_{2} \mathrm{O}_{3}$ gas sensors to $100 \mathrm{ppm}$ ethanol under different operating temperatures, (a) $\mathrm{Mo}_{0} \mathrm{In}$, (b) $\mathrm{Mo}_{1} \mathrm{In}$, (c) $\mathrm{Mo}_{3} \mathrm{In},(\mathrm{d}) \mathrm{Mo}_{5} \mathrm{In}$. 
presents the detailed initial resistance of as-prepared gas sensors under different operating temperature. It is worth noting that the resistance of gas sensors decreased with the increasing of the operating temperature, and the $\mathrm{Mo}_{1} \mathrm{In}$ gas sensor exhibits the highest resistance than other sensors under different operating temperature.

The response and recovery time are also important sensing characteristics of a gas sensor. Fig. 8(a) illustrates the response/ recovery curves of as-prepared $\operatorname{In}_{2} \mathrm{O}_{3}$ gas sensors to $100 \mathrm{ppm}$ ethanol vapor at $185{ }^{\circ} \mathrm{C}$. It can be clearly observed that the response of gas sensor increases fast and reach to the stable value when exposed to ethanol. However, after the pumping ethanol gas away, the sensor response slowly returned to its initial value. At optimized operating temperature $\left(185^{\circ} \mathrm{C}\right)$, the measured response and recovery time for $\mathrm{Mo}_{3}$ In sensor is about $11 \mathrm{~s}$ and $94 \mathrm{~s}$, respectively. Fig. 8(b) displays the detailed information of response and recovery times for the as-prepared $\mathrm{In}_{2} \mathrm{O}_{3}$ gas sensors. From the measured curves, it can be clearly observed that the response time is ranged from $9 \mathrm{~s}$ to $12 \mathrm{~s}$ for $100 \mathrm{ppm}$ ethanol vapor, whereas the recovery time varied from $68 \mathrm{~s}$ to $94 \mathrm{~s}$. The results demonstrate that the response time is much shorter than the recovery time for all the gas sensors. Meanwhile, the response and recovery values as a function of operating temperature to $100 \mathrm{ppm}$ ethanol for all the gas sensors are shown in Fig. S4 (ESI S4†). Compared with the lower temperature, we can find that all the as-fabricated $\operatorname{In}_{2} \mathrm{O}_{3}$ gas sensors exhibit faster response and recovery times at higher temperature.

To further evaluate the gas sensing properties of as-prepared sensors, the dynamic response transient characteristics were conducted on $\operatorname{In}_{2} \mathrm{O}_{3}$ gas sensors under different concentrations of ethanol (1-800 ppm) at $185{ }^{\circ} \mathrm{C}$, as shown in Fig. 9(a). When exposed to ethanol, the responses of all the gas sensors increase fast with the increasing concentration of ethanol. Meanwhile, it is noteworthy that the $\mathrm{Mo}_{3}$ In gas sensor exhibits the highest response compared with others gas sensors, which indicates the enhanced gas sensing properties. Fig. 9(b) illustrates the response plots of $\operatorname{In}_{2} \mathrm{O}_{3}$ gas sensors versus ethanol concentration in the range of 1-800 ppm at optimum working temperature. It is obvious that the response values of gas sensors grow with the increasing concentration of ethanol (1-200 ppm). However, the responses of gas sensors exhibit the tendency of plateau as further increase the concentration of ethanol vapour. This phenomenon can be explained as follows: with the
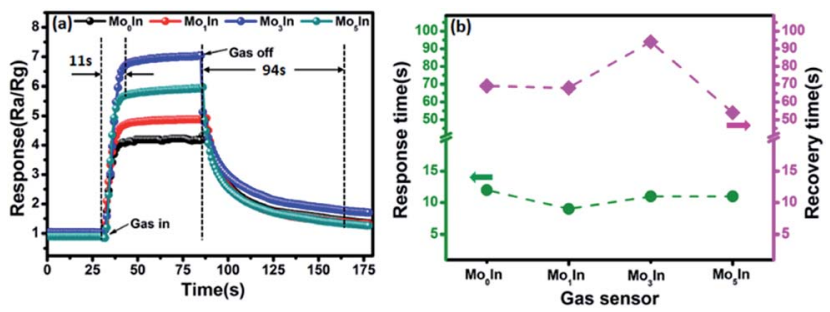

Fig. 8 (a) Dynamic response-recovery behavior of $\ln _{2} \mathrm{O}_{3}$ gas sensors toward $100 \mathrm{ppm}$ ethanol at $185^{\circ} \mathrm{C}$, (b) response/recovery time of $\mathrm{In}_{2} \mathrm{O}_{3}$ gas sensors to $100 \mathrm{ppm}$ ethanol at $185^{\circ} \mathrm{C}$.
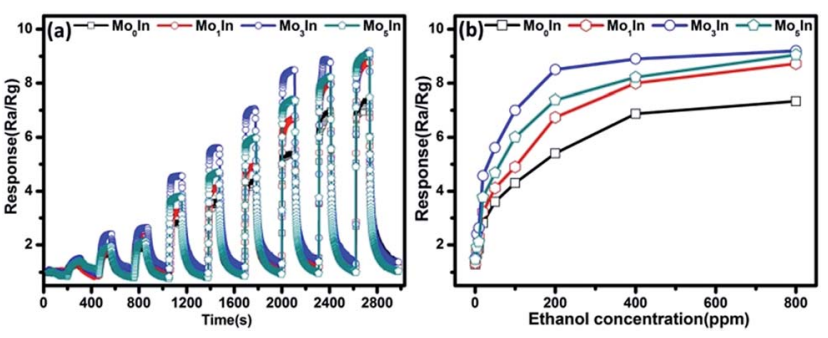

Fig. 9 (a) Dynamic response transient of the gas sensor to different concentrations of ethanol at $185^{\circ} \mathrm{C}$. (b) Responses versus ethanol concentration for $\ln _{2} \mathrm{O}_{3}$ gas sensors at $185^{\circ} \mathrm{C}$.

increasing concentration of ethanol, the response of gas sensor was determined by the surface reaction rate. Because there are insufficient adsorption sites, the response easily presents the status of saturation, and the similar results have been reported in previous literatures. ${ }^{22,38}$ Fig. S5 (ESI S5 $†$ ) displays the real time resistance curves of as-prepared sensors toward different concentrations of ethanol vapour (1-800 ppm). It can be clearly observed that the resistance of the pure and Mo-loaded $\operatorname{In}_{2} \mathrm{O}_{3}$ gas sensors drastically decreased upon exposure to ethanol vapour and rapidly increased when the gas was removed. Furthermore, the resistance of $\mathrm{Mo}_{3} \mathrm{In}$ gas sensor can return to its original value after a response and recovery cycle comparing with $\mathrm{Mo}_{0}$ In sensor, which indicates the good stability of $\mathrm{Mo}_{3} \mathrm{In}$ sensor.

In order to assess the detection limit, the gas sensing experiments were conducted on the as-fabricated gas sensors to low concentrations (50-500 ppb) of ethanol vapour under the optimum operating temperature. Fig. 10 depicts the transient response of gas sensors sequentially exposed to $50 \mathrm{ppb}, 100$ $\mathrm{ppb}, 200 \mathrm{ppb}, 300 \mathrm{ppb}, 400 \mathrm{ppb}$ and $500 \mathrm{ppb}$ ethanol at $185^{\circ} \mathrm{C}$, respectively. The measured responses of all the gas sensors show an obvious increase with the increasing concentration of
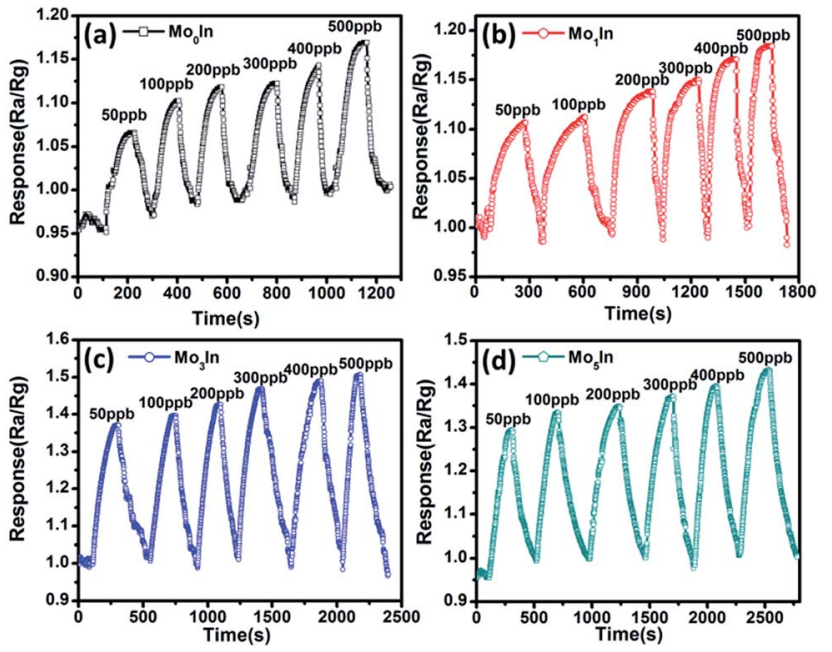

Fig. 10 Dynamic response curves of as-prepared gas sensors to low concentrations of ethanol (50-500 ppb) at $185^{\circ} \mathrm{C}$, (a) Mooln, (b) $\mathrm{Mo}_{1} \mathrm{In}$, (c) $\mathrm{Mo}_{3} \mathrm{In},(\mathrm{d}) \mathrm{Mo}_{5} \mathrm{In}$. 
ethanol. Meanwhile, Fig. S6 (ESI S6†) illustrates the response curves of gas sensors to low concentrations of ethanol, and the measured results demonstrate that the introduction of Mo element can significantly improve the gas sensing performance. Especially, the $\mathrm{Mo}_{3}$ In sensor exhibits the highest gas response, and the measured response can reach to 1.5 even for $500 \mathrm{ppb}$ ethanol. In addition, the obtained detection limit of $\mathrm{Mo}_{3} \mathrm{In}$ sensor can down to $50 \mathrm{ppb}$, which indicates that the as-prepared $\mathrm{Mo}_{3}$ In gas sensor has a potential for lower concentration of ethanol detection.

The selectivity is another key parameter for gas sensor, which is also crucial for practical application. Fig. 11(a) displays the responses of pure and Mo-loaded $\mathrm{In}_{2} \mathrm{O}_{3}$ gas sensors to various gases under the concentration of $100 \mathrm{ppm}$ at $185^{\circ} \mathrm{C}$ including ethanol, methanol, methane, carbon monoxide and hydrogen. It is noted that the as-prepared $\operatorname{In}_{2} \mathrm{O}_{3}$ gas sensors exhibit higher responses to ethanol compared with other testing gases. Meanwhile, the measured response of Mo-loaded $\mathrm{In}_{2} \mathrm{O}_{3}$ gas sensors to ethanol are significantly larger than that of pure $\mathrm{In}_{2} \mathrm{O}_{3}$ gas sensor, which prove the gas sensing performances of $\mathrm{In}_{2} \mathrm{O}_{3}$ has been effectively enhanced by Mo loading.

For practical applications, gas sensors not only need to present high response and good selectivity to the target gases, but also ensure excellent their long-term reliability. Therefore, the long-term stability experiments were conducted on the asfabricated $\mathrm{In}_{2} \mathrm{O}_{3}$ gas sensors toward $100 \mathrm{ppm}$ of ethanol over a total period of 90 days, as shown in Fig. 11(b). It is clearly shown that the maximal deviations of the responses for all the $\mathrm{In}_{2} \mathrm{O}_{3}$ gas sensors are less than $10 \%$ toward ethanol, which exhibit the excellent stability of sensors.

\subsection{Gas-sensing mechanism}

It is well known that $\operatorname{In}_{2} \mathrm{O}_{3}$ is an n-type semiconducting chemiresistive oxide sensor material. The gas sensing mechanism for the $\mathrm{In}_{2} \mathrm{O}_{3}$ gas sensor was explained on the basis of an interaction mechanism for the adsorption of ethanol onto $\operatorname{In}_{2} \mathrm{O}_{3}$ microstructures. As an electron donor, $\mathrm{In}_{2} \mathrm{O}_{3}$ can provide electrons because of the existence of oxygen vacancy $\left(\mathrm{V}_{\mathrm{o}}\right)$ in the gas sensing material. ${ }^{39-41}$ When $\operatorname{In}_{2} \mathrm{O}_{3}$ gas sensor exposed to fresh air, the oxygen molecules in air will be adsorbed on the surface of $\mathrm{In}_{2} \mathrm{O}_{3}$ through capturing free electrons from conduction band and form reactive oxygen species such as $\mathrm{O}^{2-}, \mathrm{O}_{2}{ }^{-}$and $\mathrm{O}^{-}$,
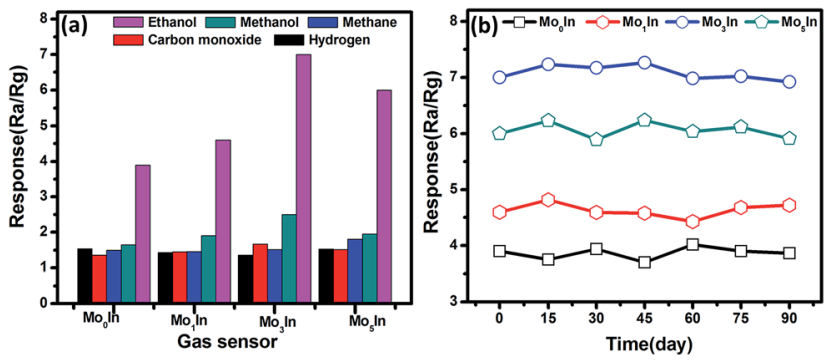

Fig. 11 (a) Response of as-prepared $\ln _{2} \mathrm{O}_{3}$ gas sensors to $100 \mathrm{ppm}$ various gases at $185^{\circ} \mathrm{C}$. (b) The long term stability of $\ln _{2} \mathrm{O}_{3}$ gas sensors to $100 \mathrm{ppm}$ ethanol. leading to the creation of a depletion region and the increase of the resistance. ${ }^{\mathbf{2 1 , 2 2 , 2 6}}$ When exposed to reducing gas like ethanol in this work, the ethanol gas molecules react with the reactive oxygen ions as the following reactions: $:^{15,42}$

$$
\begin{gathered}
\mathrm{CH}_{3} \mathrm{CH}_{2} \mathrm{OH}_{(\mathrm{gas})} \rightleftharpoons \mathrm{CH}_{3} \mathrm{CH}_{2} \mathrm{OH}_{(\mathrm{ads})} \\
6 \mathrm{O}_{(\mathrm{ads})}{ }^{-}+\mathrm{CH}_{3} \mathrm{CH}_{2} \mathrm{OH}_{(\mathrm{ads})}=2 \mathrm{CO}_{2(\mathrm{gas})}+3 \mathrm{H}_{2} \mathrm{O}_{(\mathrm{gas})}+6 \mathrm{e}^{-}
\end{gathered}
$$

As shown in the reactions (1) and (2), the trapped electrons are released back to the conduction band of the $\operatorname{In}_{2} \mathrm{O}_{3}$. This reaction causes the resistance of the $\operatorname{In}_{2} \mathrm{O}_{3}$ gas sensor decrease and induces the gas sensing.

For the Mo-loaded $\operatorname{In}_{2} \mathrm{O}_{3}$ microstructures (Fig. 12(a)), the enhancement of gas response can be attributed to the reasons as follows: on the one hand, there is a synergetic effect on gas target due to that both $\mathrm{In}_{2} \mathrm{O}_{3}$ and $\mathrm{MoO}_{3}$ are n-type semiconducting metal oxide materials, and this effect has also been found in other composites. ${ }^{\mathbf{4 3 4}}$ Fig. 12(b) and (c) illustrates the partial enlarged section of the $\mathrm{MoO}_{3}-\mathrm{In}_{2} \mathrm{O}_{3}$ junction after exposure to fresh air and ethanol, respectively. It is clearly seen that the reactions happened at the section of $\mathrm{MoO}_{3}$ are the same as what on the surface of $\operatorname{In}_{2} \mathrm{O}_{3}$, which have a positive effect for the response of gas sensor. On the other hand, the improvement of gas response can be ascribed to the formation of $n-n$ homotype heterojunction structure between $\mathrm{In}_{2} \mathrm{O}_{3}$ and $\mathrm{MoO}_{3} \cdot{ }^{45-47}$ As show in Fig. 12(d) and (e), the band gap of $\operatorname{In}_{2} \mathrm{O}_{3}\left(E_{\mathrm{g}}=3.75 \mathrm{eV}\right)$ is higher than that of $\mathrm{MoO}_{3}\left(E_{\mathrm{g}}=3.15 \mathrm{eV}\right)$, and electrons are transported from $\mathrm{MoO}_{3}$ to $\mathrm{In}_{2} \mathrm{O}_{3}$, leading to the formation of an accumulation layer and a depletion layer at the interface of $\operatorname{In}_{2} \mathrm{O}_{3}$ and $\mathrm{MoO}_{3}$, respectively. The subsequent oxygen adsorption makes the accumulation layer depleted in air, resulting in a further increase of resistance. Compared with pure $\operatorname{In}_{2} \mathrm{O}_{3}$ gas sensor, the larger change of resistance for $\mathrm{MoO}_{3} / \mathrm{In}_{2} \mathrm{O}_{3}$ composite material can be measured upon exposure to fresh air and ethanol, which results in the improvement of the sensing properties.

Furthermore, the high selectivity of gas sensor to ethanol could be explained in the following reasons: for one thing, the

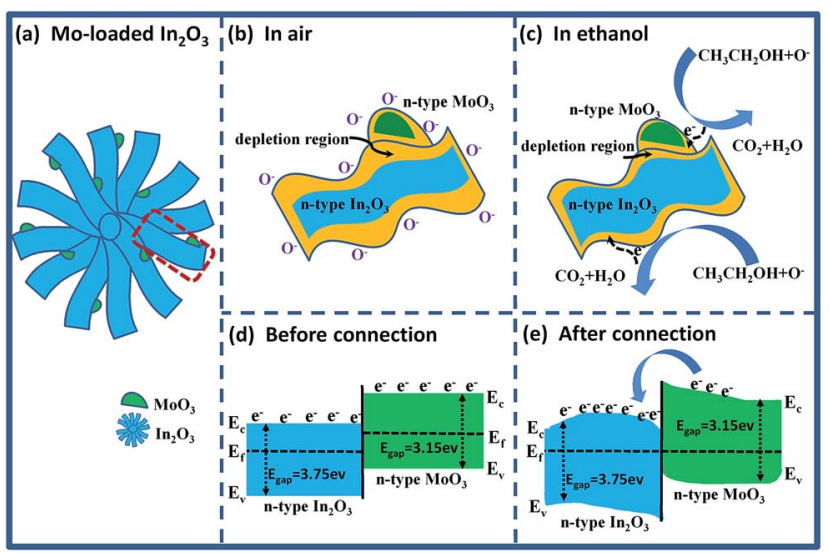

Fig. 12 (a) Schematic diagram of Mo-loaded $\ln _{2} \mathrm{O}_{3}$ microstructures, (b and c) Mo-loaded $\ln _{2} \mathrm{O}_{3}$ microstructures exposed in air and ethanol, (d and e) energy band of Mo-loaded $\ln _{2} \mathrm{O}_{3}$ microstructures before and after connection, respectively. 
stability of compound is greatly affected by the bond energy. The higher the bond energy, the harder the bond breaks. It is well known that the bond strengths of $\mathrm{C}-\mathrm{H}, \mathrm{C}-\mathrm{C}, \mathrm{C}=\mathrm{O}, \mathrm{H}-\mathrm{H}$ and $\mathrm{O}-\mathrm{H}$ are $411,345,748.2,436,462 \mathrm{~kJ} \mathrm{~mol}^{-1}$, respectively, ${ }^{48}$ which indicates that the ethanol is relatively unstable due to the lowest bond energy of $\mathrm{C}-\mathrm{C}$ in ethanol. Compared with these detected gases (methanol, methane, carbon monoxide, hydrogen), the higher reducing ability of ethanol results in the significant response. For another thing, many previous works have been reported that the gas sensing response of basic oxides was improved in terms of the reactive functional group or the complex molecular structure such as ethanol.99,50 An electronliberate theory was used to elucidate the experimental results (for instance, methanol, hydrogen and carbon monoxide). The reactions can be expressed as follows: ${ }^{51,52}$

$$
\begin{gathered}
3 \mathrm{O}_{(\text {ads })}{ }^{-}+\mathrm{CH}_{3} \mathrm{OH}_{(\mathrm{ads})}=\mathrm{CO}_{2(\text { gas })}+2 \mathrm{H}_{2} \mathrm{O}_{(\mathrm{gas})}+3 \mathrm{e}^{-} \\
\mathrm{O}_{(\text {ads })}{ }^{-}+\mathrm{CO}_{(\mathrm{ads})}=\mathrm{CO}_{2(\text { gas })}+\mathrm{e}^{-} \\
\mathrm{O}_{(\mathrm{ads})}{ }^{-}+\mathrm{H}_{2(\mathrm{ads})}=\mathrm{H}_{2} \mathrm{O}_{(\mathrm{gas})}+\mathrm{e}^{-}
\end{gathered}
$$

Form the reactions (2)-(5), it is clearly seen that the ethanol gas can release more electrons under the same concentration comparing with other gases, which could be the other way to explain the better selectivity to ethanol.

\section{Conclusions}

Flower-like $\mathrm{MoO}_{3} / \mathrm{In}_{2} \mathrm{O}_{3}$ microstructures with different contents of Mo element were synthesized by hydrothermal method. Characterization results showed that the obtained flower-like microstructure were about $4 \mu \mathrm{m}$ in size and composed of numerous nanosheets. Comparing with pure $\operatorname{In}_{2} \mathrm{O}_{3}$ gas sensor, the Mo-loaded $\operatorname{In}_{2} \mathrm{O}_{3}$ gas sensors exhibits better gas sensing performance for ethanol detection, including high response, fast response and recovery time, low detection limit, good selectivity and stability. This improvement could be attributed to synergetic effect as well as the $\mathrm{n}-\mathrm{n}$ homotype heterojunction structure between $\mathrm{In}_{2} \mathrm{O}_{3}$ and $\mathrm{MoO}_{3}$, which provide sufficient active surfaces. However, excessive amount of $\mathrm{MoO}_{3}$ in the samples will suppress the detection sensibility of $\operatorname{In}_{2} \mathrm{O}_{3}$. In particular, optimization of the Mo content in the $\operatorname{In}_{2} \mathrm{O}_{3}$ hierarchical microstructures has proved that the optimum Mo load should be about $3 \mathrm{~mol} \%$ ensuring the best gas sensing properties of the ethanol sensor.

\section{Acknowledgements}

This work was financially supported by the National Natural Science Foundation of China (51205274), Higher school science and technology innovation project of Shanxi (2016137), Natural Science of Shanxi Province (2016011039), Talent project of Shanxi Province (201605D211036), Science and Technology Major Project of the Shan Xi Science and Technology Department (20121101004), Key Disciplines Construction in Colleges and Universities of Shanxi ([2012]45).

\section{Notes and references}

1 H. J. Zhang, R. F. Wu, Z. W. Chen, G. Liu, Z. N. Zhang and Z. Jiao, CrystEngComm, 2012, 14, 1775-1782.

2 F. Song, H. L. Su, J. J. Chen, W. J. Moon, W. M. Lau and D. Zhang, J. Mater. Chem., 2012, 22, 1121-1126.

3 L. L. Liu, S. C. Li, X. Guo, L. Y. Wang, L. Liu and X. S. Wang, J. Mater. Sci.: Mater. Electron., 2016, 27, 5153-5157.

4 X. Q. An, J. C. Yu, Y. Wang, Y. M. Hu, X. L. Yu and G. J. Zhang, J. Mater. Chem., 2012, 22, 8525-8531.

5 H. Liu, X. W. Du, X. R. Xing, G. X. Wang and S. Z. Qiao, Chem. Commun., 2012, 48, 865-867.

6 A. Aslani and V. Oroojpour, Phys. B, 2011, 406, 144-149.

7 C. H. Feng, W. Li, C. Li, L. H. Zhu, H. F. Zhang, Y. Zhang, S. P. Ruan, W. Y. Chen and L. X. Yu, Sens. Actuators, B, 2012, 166, 83-88.

8 X. M. Zou, J. L. Wang, X. Q. Liu, C. L. Wang, Y. Jiang, Y. Wang, X. H. Xiao, J. C. Ho, J. C. Li, C. Z. Jiang, Y. Fang, W. Liu and L. Liao, Nano Lett., 2013, 13, 3287-3292.

9 H. X. Yang, L. Liu, H. Liang, J. J. Wei and Y. Z. Yang, CrystEngComm, 2011, 13, 5011-5016.

10 H. Zhao, H. X. Dong, L. N. Zhang, X. W. Wang and H. Q. Yang, Mater. Chem. Phys., 2011, 130, 921-931.

11 C. S. Rout, K. Ganesh, A. Govindaraj and C. N. R. Rao, Appl. Phys. A, 2006, 85, 241-246.

12 Y. Cao, J. Zhao, X. X. Zou, P. P. Jin, H. Chen, R. Q. Gao, L. J. Zhou, Y. C. Zou and G. D. Li, RSC Adv., 2015, 5, 54245431.

13 S. Elouali, L. G. Bloor, R. Binions, I. P. Parkin, C. J. Carmalt and J. A. Darr, Langmuir, 2012, 28, 1879-1885.

14 X. H. Sun, H. M. Ji, X. L. Li, S. Cai and C. M. Zheng, Mater. Lett., 2014, 120, 287-291.

15 S. An, S. Park, H. Ko, C. Jin, W. I. Lee and C. Lee, J. Phys. Chem. Solids, 2013, 74, 979-984.

16 M. Hashimoto, S. Ujiie and A. Mori, Adv. Mater., 2003, 15, 797-800.

17 Y. F. Hao, G. W. Meng, C. H. Ye and L. D. Zhang, Cryst. Growth Des., 2005, 5, 1617-1621.

18 T. Gao and T. H. Wang, J. Cryst. Growth, 2006, 290, 660-664. 19 Y. J. Sun, Z. T. Zhao, P. W. Li, G. Li, Y. Chen, W. D. Zhang and J. Hu, Appl. Surf. Sci., 2015, 356, 73-80.

20 W. Yang, P. Wan, X. D. Zhou, J. M. Hu, Y. F. Guan and L. Feng, ACS Appl. Mater. Interfaces, 2014, 6, 21093-21100.

21 X. W. Li, J. Y. Liu, H. Guo, X. Zhou, C. Wang, P. Sun, X. L. Hu and G. Y. Lu, RSC Adv., 2015, 5, 545-551.

22 X. P. Shen, L. J. Guo, G. X. Zhu, C. Y. Xi, Z. Y. Ji and H. Zhou, RSC Adv., 2015, 5, 64228-64234.

23 X. Y. Lai, P. Li, T. L. Yang, J. C. Tu and P. Xue, Scr. Mater., 2012, 67, 293-296.

24 W. W. Chen, Y. K. Liu, Z. J. Qin, Y. M. Wu, S. H. Li and P. Ai, Sensors, 2015, 15, 29950-29957.

25 D. Han, P. Song, S. Zhang, H. H. Zhang, Q. Xu and Q. Wang, Sens. Actuators, B, 2015, 216, 488-496.

26 W. Zheng, X. F. Lu, W. Wang, Z. Y. Li, H. N. Zhang, Z. J. Wang, X. R. Xu, S. Y. Li and C. Wang, J. Colloid Interface Sci., 2009, 338, 366-370. 
27 X. Chi, C. B. Liu, L. Liu, S. C. Li, H. Y. Li, X. B. Zhang, X. Q. Bo and H. Shan, Mater. Sci. Semicond. Process., 2014, 18, 160164.

28 S. S. Farvid, M. Hegde and P. V. Radovanovic, Chem. Mater., 2013, 25, 233-244.

29 J. Hu, F. Q. Gao, Z. T. Zhao, S. B. Sang, P. W. Li, W. D. Zhang, X. T. Zhou and Y. Chen, Appl. Surf. Sci., 2016, 363, 181-188.

30 S. S. Yi, J. B. Cui, S. Li, L. J. Zhang, D. J. Wang and Y. H. Lin, Appl. Surf. Sci., 2014, 319, 230-236.

31 N. R. Yogamalar and A. C. Bose, J. Alloys Compd., 2011, 509, 8493-8500.

32 A. Gurlo, N. Barsan, U. Weimar, M. Ivanovskaya, A. Taurino and P. Siciliano, Chem. Mater., 2003, 23, 4377-4383.

33 Q. Liu, W. Zhang, R. Liu and G. B. Mao, Eur. J. Inorg. Chem., 2015, 5, 845-851.

34 C. Tao, S. P. Ruan, X. D. Zhang, G. H. Xie, L. Shen, X. Z. Kong, W. Dong, C. X. Liu and W. Y. Chen, Appl. Phys. Lett., 2008, 93, 193307.

35 J. Swiatowska-Mrowiecka, S. de Diesbach, V. Maurice, S. Zanna, L. Klein, E. Briand, I. Vickridge and P. Marcus, J. Phys. Chem. C, 2008, 112, 11050-11058.

36 Y. D. Zhang, Z. Zheng and F. L. Yang, Ind. Eng. Chem. Res., 2010, 49, 3539-3543.

37 F. Li, S. J. Guo, J. L. Shen, L. Shen, D. M. Sun, B. Wang, Y. Chen and S. P. Ruan, Sens. Actuators, B, 2017, 238, 364373.

38 C. Q. Ge, C. S. Xie and S. Z. Cai, Mater. Sci. Eng., B, 2007, 137, 53-58.

39 C. S. Rout, K. Ganesh, A. Govindaraj and C. N. R. Rao, Appl. Phys. A, 2006, 85, 241-246.
40 L. Liao, H. B. Lu, J. C. Li, H. He, D. F. Wang, D. J. Fu and C. Liu, J. Phys. Chem. C, 2007, 111, 1900-1903.

41 S. Xu, J. Gao, L. L. Wang, K. Kan, Y. Xie, P. K. Shen, L. Li and K. Y. Shi, Nanoscale, 2015, 7, 14643-14651.

42 T. T. Wang, S. Y. Ma, L. Cheng, J. Luo, X. H. Jiang and W. X. Jin, Sens. Actuators, B, 2015, 216, 212-220.

43 P. Sun, Y. X. Cai, S. S. Du, X. M. Xu, L. You, J. Ma, F. M. Liu, X. S. Liang, Y. F. Sun and G. Y. Lu, Sens. Actuators, B, 2013, 182, 336-343.

44 B. P. J. de Lacy Costello, R. J. Ewen, N. M. Ratcliffe and P. S. Sivanand, Sens. Actuators, B, 2003, 92, 159-166.

45 P. Li, H. Q. Fan and Y. Cai, Sens. Actuators, B, 2013, 185, 110116.

46 W. L. Zang, Y. X. Nie, D. Zhu, P. Deng, L. L. Xing and X. Y. Xue, J. Phys. Chem. C, 2014, 118, 9209-9216.

47 W. Zeng, T. M. Liu and Z. C. Wang, Phys. E, 2010, 43, 633638.

48 X. F. Chu, S. M. Liang, W. Q. Sun, W. B. Zhang, T. Y. Chen and Q. F. Zhang, Sens. Actuators, B, 2010, 148, 399-403.

49 J. Q. Xu, J. J. Han, Y. Zhang, Y. A. Sun and B. Xie, Sens. Actuators, B, 2008, 132, 334-339.

50 H. Men, P. Gao, B. B. Zhou, Y. J. Chen, C. L. Zhu, G. Xiao, L. Q. Wang and M. L. Zhang, Chem. Commun., 2010, 46, 7581-7583.

51 P. Song, Q. Wang and Z. X. Yang, Sens. Actuators, B, 2011, 156, 983-989.

52 P. Song, H. H. Zhang, D. Han, J. Li, Z. X. Yang and Q. Wang, Sens. Actuators, B, 2014, 196, 140-146. 